\title{
A new type of loriciferan larva (Shira larva) from the deep sea of Shatsky Rise, Pacific Ocean
}

\author{
Ricardo Cardoso Neves • Reinhardt Møbjerg Kristensen
}

Received: 26 July 2013 / Accepted: 16 October 2013 /Published online: 1 November 2013

(C) Gesellschaft für Biologische Systematik 2013

\begin{abstract}
Loricifera is a phylum of minute animals that live exclusively in marine sediments. A total of 33 species have been described so far in this phylum; however, several more are already known from preliminary observations. Loriciferans are characterised by a complex life cycle, which involves a succession of several adult and larval stages. Here, we describe a new type of loriciferan larval stage: the Shira larva. The gross morphology of this larva is generally similar to that of the most prominent larval type of Loricifera, the so-called Higgins larva. However, the Shira larva possesses a number of unique features, namely (1) a single pair of anteroventral setae is present in the most anterior region of the abdomen, (2) the bases of the anteroventral setae are very large and swollen, (3) the thorax and abdomen are thinner than the introvert and (4) the abdominal region is divided into five sub-regions. Accordingly, we described the new species, Tenuiloricus shirayamai gen. nov. et sp. nov. (incertae sedis). The new findings are discussed from a comparative perspective with the Higgins larva as well as with the fossil of a putative loriciferan larval stage from the Middle Cambrian.
\end{abstract}

Keywords Loricifera $\cdot$ Lifecycle $\cdot$ Morphology $\cdot$ Taxonomy $\cdot$ Systematics $\cdot$ Evolution

\section{Introduction}

Loricifera is a phylum of exclusively marine animals found inhabiting the sediments of the sea floor worldwide. These

R. C. Neves $(\bowtie)$

Biozentrum, University of Basel, Klingelbergstrasse 50, 4056 Basel, Switzerland

e-mail: ricardon.6@gmail.com

R. M. Kristensen

Natural History Museum of Denmark, Universitetsparken 15,

2100 Copenhagen Ø, Denmark microscopic organisms $(80-800 \mu \mathrm{m})$ dwell in the interstices between sand, shell gravel and mud from the intertidal zone to the deep sea (Kristensen 1991a). After the description of the first loriciferan, Nanaloricus mysticus Kristensen, 1983, the phylum accommodates presently 33 species distributed in a single order, Nanaloricida, and three families, Nanaloricidae, Pliciloricidae and Urnaloricidae (Kristensen 1983; Higgins and Kristensen 1986; Heiner and Kristensen 2008; Bang-Berthelsen et al. 2012). So far, a total of ten loriciferan genera have been assigned to these three families: (1) Nanaloricus, Armorloricus, Phoeniciloricus, Spinoloricus, Culexiregiloricus and Australoricus in family Nanaloricidae (Kristensen 1983; Kristensen and Gad 2004; Gad 2004; Heiner and Neuhaus 2007; Gad 2009a; Heiner et al. 2009); (2) Pliciloricus, Rugiloricus and Titaniloricus in family Pliciloricidae (Higgins and Kristensen 1986; Gad 2005a); and (3) Urnaloricus in family Urnaloricidae (Heiner and Kristensen 2008). However, many new species (and even new genera) may have been subjected to preliminary examinations in recent doctoral dissertations although formal descriptions were never accomplished (cf. Gad 2005b; Bang-Berthelsen 2008). In addition, an as yet undescribed species of the genus Nanaloricus was the focus of a recent study on the adult myoanatomy of Loricifera (Neves et al. 2013).

The body of adult loriciferans is divided into head (mouth cone and introvert), neck, thorax and abdomen (Kristensen 1991a, b; Bang-Berthelsen et al. 2012). The mouth cone ends in a terminal mouth opening, and in some species is characterized by the presence of internal and/or external armature. The introvert carries several rows of leg- or spinelike appendages that are cuticularised structures with a locomotory or sensory function. The neck region possesses either 15 single trichoscalids or 7 double alternating with 8 single trichoscalids (i.e. thin appendages with hairy surface and/or serrated margins), while the thorax is accordion-like and lacks appendages. Posteriorly, a cuticular exoskeleton called a lorica encases the abdomen. In the adults of family Nanaloricidae, the lorica is composed of six to ten plates, 
while in Pliciloricidae the lorica is a single structure characterised by several longitudinal folds named plicae. Adults of the family Urnaloricidae are not known. In addition, the lorica possesses sensory structures called flosculi, which can be a flower-shaped collar of microvilli with a central cilium (Nanaloricus-type) or a small, round papilla with a very thin cuticle (Pliciloricus -type).

The most prominent larval stage of Loricifera is the so-called Higgins larva (Kristensen 1991a, b; Bang-Berthelsen et al. 2012). The body of this larval stage is also divided into head (mouth cone and introvert), neck, thorax and abdomen. Different from the adults, the head appendages might be arranged as functional elements rather than in rows. Furthermore, the neck lacks appendages and several setae are associated with the larval lorica. These setae are arranged in two groups of two to three pairs; one group of locomotory/ sensory setae is located ventrally at the most anterior edge of the lorica, while a second group of setae with a sensory role is located in the most posterior region of the abdomen. Flosculi of the Nanaloricus -type are located posteriorly in the abdomen of nanaloricids and of some species of Pliciloricus. A unique feature in the Higgins larva is the presence of a pair of flipper- or spine-like posterior toes used for locomotion. In the family Nanaloricidae (except in genus Phoeniciloricus; cf. Gad 2004), the toes possess large basal structures called mucrones, which are usually round or leafshaped.

The family Nanaloricidae is characterised by a relatively simple sexual life cycle (Kristensen and Brooke 2002). Briefly, the embryo develops into a Higgins larva that molts several times until it metamorphoses into a juvenile form called a postlarva. Afterwards, the postlarva molts into a male or a female that is able to reproduce sexually and thus completes the life cycle. In contrast, the life cycle of family Pliciloricidae is very complex because they can undergo both sexual and asexual reproduction. The asexual alternative life cycle involves several intermediate stages and reduced larval forms, such as the ghost-larva (Heiner 2008). This reduced larval stage possesses a retracted introvert and, in some cases, a single ovary in which embryos develop parthenogenetically into a Higgins larva. Externally, several rows of introvert scalids and pairs of abdominal ventral setae may be present. Furthermore, a hermaphroditic phase is described in the life cycle of genus Rugiloricus (Gad 2005b, c; Kristensen et al. 2013). The life cycle of family Urnaloricidae is not known in detail although a different type of intermediate larva is involved - the pre mega-larva, which is the result of metamorphosis of the last instar Higgins larva (Heiner and Kristensen 2008). The gross morphology of the pre megalarva is characterised by several rows of scalids in a reduced introvert, internal buccal armature and a large ovary with few oocytes. The pre mega-larva apparently molts into a cystforming mega-larva, which possesses two reduced larval stages inside: the ghost larva (similar to that found in family Pliciloricidae) and a presumed postlarva.

The actual diversity of the loriciferan body plan seems not to be totally known yet. Indeed, new life cycle stages are often discovered, which provides new insights into the complex life cycle of Loricifera. This is the case for, e.g. the hermaphroditic adult of Rugiloricus doliolius and Rugiloricus renaudae, the pre mega-larva of Urnaloricus gadi or the highly reduced postlarval stage of Rugiloricus manuelae (Gad 2005b, c; Heiner and Kristensen 2008; Kristensen et al. 2013; Pardos and Kristensen 2013). Here, we describe the new species, Tenuiloricus shirayamai gen. nov. et sp. nov. (incertae sedis), which is characterized by a new type of loriciferan larval stage, the Shira larva. Although morphologically similar to the Higgins larva, the Shira larva possesses unique features. We discuss this new finding by comparing the gross morphology of the Shira larva with that of the Higgins larva and also with the fossil of a putative loriciferan larval stage from the Middle Cambrian (Maas et al. 2009).

\section{Materials and methods}

The description presented here is based on a single specimen collected by Professor Dr. Yoshihisa Shirayama, during an expedition (cruise KH-80-3) to the northern Pacific Ocean on board the RV Hakuhô Maru (Ocean Research Institute, University of Tokyo). The single larval specimen was found on 30 July 1980 in calcareous ooze from the oceanic plateaus known as Shatsky Rise $\left(32^{\circ} 00^{\prime} 10^{\prime \prime} \mathrm{N}-158^{\circ} 38^{\prime} 80^{\prime \prime} \mathrm{E}\right.$; station SC-15), which consists of underwater volcanic mountains located about 1,500 km off the coast of Japan (Shirayama 1984). The sediment was collected at $3,160 \mathrm{~m}$ water depth in a box core with several cylindrical sub-cores. Whole samples were fixed and preserved in a $5 \%$ formalin solution in seawater to which Rose Bengal $\left(0.5 \mathrm{gL}^{-1}\right)$ was added. Afterwards, the meiofauna was extracted from the sediment using sieves between 1,000 and $37 \mu \mathrm{m}$ and sorted under a stereomicroscope. Once sorted, the specimen described here was mounted in glycerol and the whole mount preparation was sealed with Glyceel (adapted from Higgins and Thiel 1988). In addition, seven larval stages of the genus Rugiloricus were found in the same sample. Microscopic investigations were carried out with an Olympus BX51 microscope fitted with differential interference contrast (DIC) optics, and photographs were taken with an Olympus C-3030 zoom digital camera. The drawing was made with the aid of a drawing tube mounted on a Wild M20 microscope. The holotypic larval stage is deposited at the Zoological Museum, Natural History Museum of Denmark under slide-number ZMUC-LOR-692. The new species and genus are designated on the peculiarity of its morphological features, and the terminology used in text 
and figures is adapted from Higgins and Kristensen (1986) and Kristensen (1991b).

\section{Results}

Phylum Loricifera Kristensen, 1983

New Genus Tenuiloricus gen. nov. (incertae sedis)

Type species: Tenuiloricus shirayamai gen. nov. et sp. nov.

\section{Genus diagnosis}

Shira larva Free living larva characterized by (1) a mouth cone lacking internal or external armature, (2) round introvert with six rows of scalids, (3) neck region well defined and accordion-like, (4) slender thorax thinner than introvert and (5) a five-partite abdominal region carrying anteriorly a single pair of setae and posteriorly a pair of toes and two pairs of sensory setae.

Adult stages or other intermediate stages (e.g. postlarva) were never found.

Etymology Contrary to all loriciferans, the Shira larva possesses an abdominal region that is thinner than the introvert. Therefore, the name chosen for the new genus is Tenuiloricus from the Latin words tenuis (= thin) and lorica (corset), masculine gender.

\section{Species diagnosis}

Shira larva: (1) body divided into four main body regions: head (mouth cone and introvert), neck, thorax and abdomen; (2) mouth cone round and short, without internal or external armature surrounding the hexagonal mouth opening; (3) introvert carrying six rows of scalids; (4) clavoscalids relatively long, tripartite and with pointy tips; (5) all spinoscalids much shorter comparatively to the clavoscalids; (6) first row spinoscalids bipartite, with slightly bulbous bases and tricuspid, pincer-like termini; (7) third row scalids bipartite, with more rectangular first segments and spine-like tips; (8) fourth row spinoscalids tripartite, with wide first segments and spine-like tips; (9) fifth row spinoscalids bipartite, with more triangular first segments and spine-like tips; (10) sixth row spinoscalids unsegmented, spine-like and with two different sizes alternating with each other; (11) neck accordion-like, composed by three series of plates; (12) thorax and abdomen narrower than the introvert; (13) abdomen subdivided into five sub-regions; (14) two pairs of sensory setae located posteriorly in the abdomen; (15) pair of toes located ventroterminally, mucrones absent.
Material

The material includes a single larval specimen, which is the holotype (ZMUC-LOR-692).

Etymology The species name is in honor of Prof. Dr. Yoshihisa Shirayama (Japan Agency for Marine-Earth Science and Technology, Kyoto University), who collected the specimen used in this description.

\section{Description}

The fully extended Shira larva is approximately $218 \mu \mathrm{m}$ long from the tip of the protruded mouth cone to the posterior end of the lorica, and $55 \mu \mathrm{m}$ wide at the maximum diameter of the introvert. Since only one specimen was studied, these measurements should be treated with the utmost care and no considerations can be made about the developmental instar of the specimen.

External morphology (Figs. 1 and 2): Body (Figs. 1 and 2a) sclerotized; divided into head (mouth cone and introvert), thorax, and subdivided abdomen. All body regions fully extended. Mouth cone (mc, Figs. 1 and 2a-d) short, round and lacks internal or external armature. The hexagonal mouth opening is located centrally at its most anterior region. Introvert (i, Figs. 1 and 2a, b) oval in shape, though the anterior end narrows towards the mouth cone. The oval region is characterized by several (ca. 30) fine longitudinal lines crossed by three transverse lines, which are regularly spaced. Six rows of scalids are arranged radially along the anterior-posterior axis of the introvert. The scalid arrangement is depicted in Fig. 3 as polar and planar projections.

First row with eight uniform clavoscalids (cs), which are long and divided into three segments. The first and most proximal segment is long and round in cross section. The second segment is slightly wider and much shorter than the first segment. The third and most distal segment is short and hook-like. The clavoscalids project laterally from the most anterior, narrow region of the introvert, while all scalids in the other rows protrude backwards from the wide region.

Second row of appendages $\left(\mathrm{sr}_{2}\right)$ with seven spinoscalids uniform and bipartite. The most proximal segment is slightly bulbous in the first half but the second half is narrower and round in section. The most distal segment is short and pincer-like, possessing a tricuspid shape.

The third row $\left(\mathrm{sr}_{3}\right)$ consists of nine spinoscalids uniform and bipartite. The most proximal segment is slightly round in the first half and more rectangular in the second half. The second segment is short and spine-like. 
Fig. 1 Tenuiloricus shirayamai gen. nov. et sp. nov. Schematic drawing of the external morphology of the Shira larva, ventral view. $a$ abdomen, $a_{I-V}$ abdominal subregions I-V, $a p$ abdomen row of plates, $a v s$ anteroventral seta, $b c$ buccal channel, cs clavoscalid, $i$ introvert, $l d f$ longitudinal double fold, If longitudinal fold, lo lorica, $m c$ mouth cone, mo mouth opening, $n$ neck, $n p_{1-3}$ neck row of serial plates $1-3, p b$ pharyngeal bulb, $p s_{1}$ posterodorsal seta, $p s_{2}$ posterolateral seta, $s r_{2-6}$ second to sixth scalid rows, $t$ thorax, $t p$ thorax row of plates, $t b$ toe base, $t b r$ toe base ridges, to toe

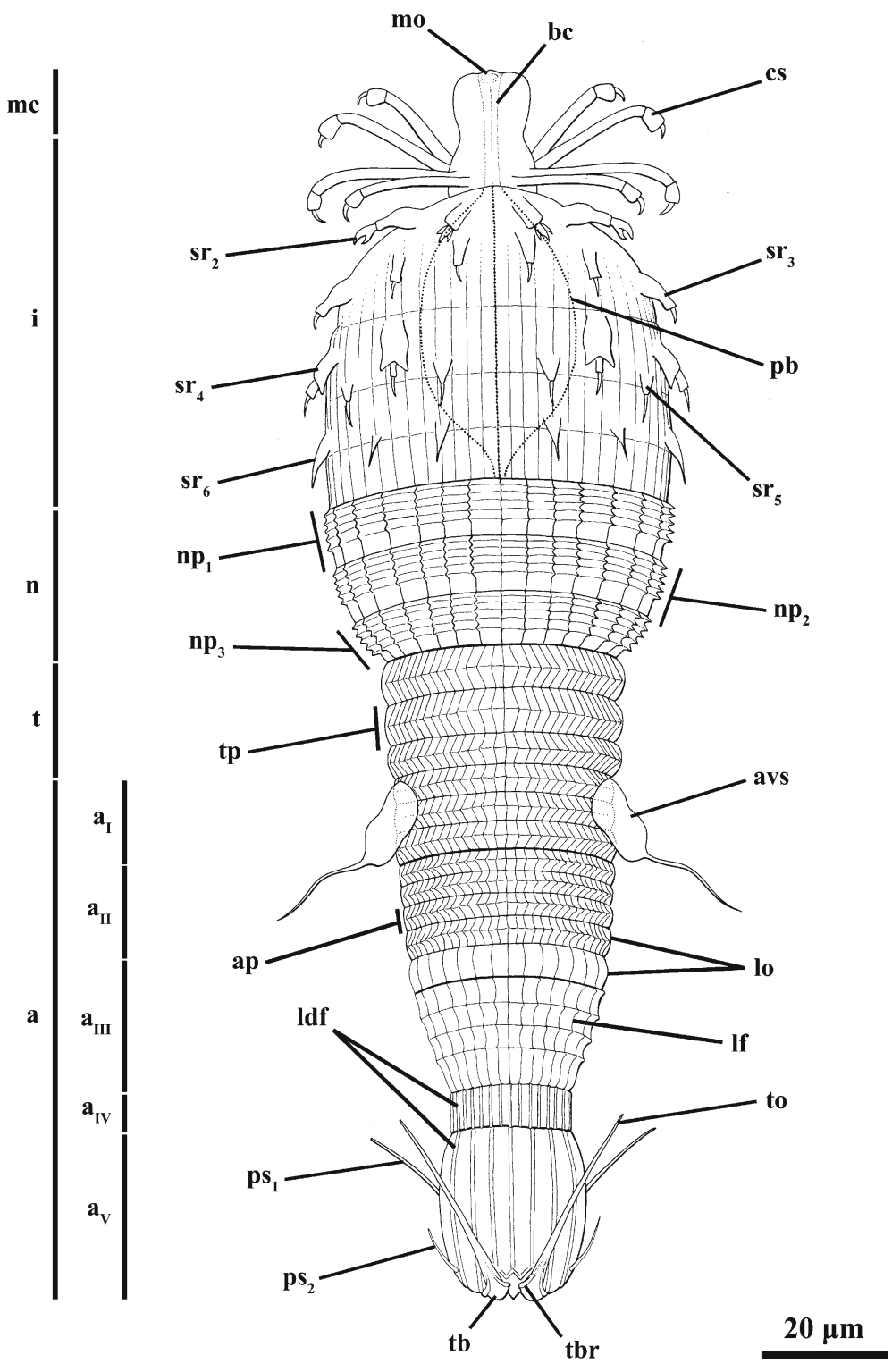

Fourth row $\left(\mathrm{Sr}_{4}\right)$ composed by seven wide, tripartite spinoscalids. The first and most proximal segment is wide and long, finishing as an inverted M-shape. The second segment is thin, short and round in section. The third and most distal segment is short and spine-like.

Fifth row $\left(\mathrm{sr}_{5}\right)$ with seven short, bipartite spinoscalids. The most proximal segment is slender and triangular, while the most distal segment is spine-like.

Sixth row $\left(\mathrm{sr}_{6}\right)$ with 13 spine-like, unsegmented spinoscalids of two different sizes: 6 of these spinoscalids are smaller and alternate with the other 7 larger and more robust.

Neck (n, Figs. 1 and 2a, b) composed of three bands of plates $\left(\mathrm{np}_{1-3}\right)$ crossed by several longitudinal folds, appearing as accordion-shaped. The plates are thus arranged in ca. 30 longitudinal series, each of them consisting of five short plates and one long plate. The neck is round in cross section though the most posterior region is narrower than the anterior region, which is the extension of the introvert.

Thorax (t, Figs. 1 and 2a) narrow and round in cross section. Several fine folds arranged longitudinally in zigzags are crossed by a number of transverse folds: two are primary and three are secondary. This arrangement gives the thorax an organization in three double rows composed of several small plates (tp).

Abdomen (a, Figs. 1 and $2 \mathrm{a}, \mathrm{e})$ divided into five subregions $\left(\mathrm{a}_{\mathrm{I}-\mathrm{V}}\right)$. The lorica (lo) seems to be more sclerotized in the two most posterior sub-regions.

The first, most anterior sub-region $\left(\mathrm{a}_{\mathrm{I}}\right)$ of the abdomen is very similar to the thorax. It has several fine folds arranged longitudinally in zigzags and crossed by two primary and three secondary transverse folds. This arrangement gives 
Fig. 2 a-e Tenuiloricus shirayamai gen. nov. et sp. nov. Differential interference contrast (DIC) light micrography, lateroventral view. a Overview of the larval body. b Close-up of the head region. $\mathbf{c}$ detail of the clavoscalids and first row spinoscalids. d detail on scalids. $\mathbf{e}$ close-up of the abdominal region and toes. $a_{I-V}$ abdominal subregions $\mathrm{I}-\mathrm{V}$, avs anteroventral seta, cs clavoscalid, $l d f$ longitudinal double fold, $l f$ longitudinal fold, $m c$ mouth cone, $n$ neck, $n p_{1-3}$ neck row of serial plates 1-3, $p s_{1}$ posterodorsal seta, $s r_{2-6}$ second to sixth scalid rows (fifth row not visible), $t$ thorax, $t b$ toe base, to toe, arrowhead mouth opening
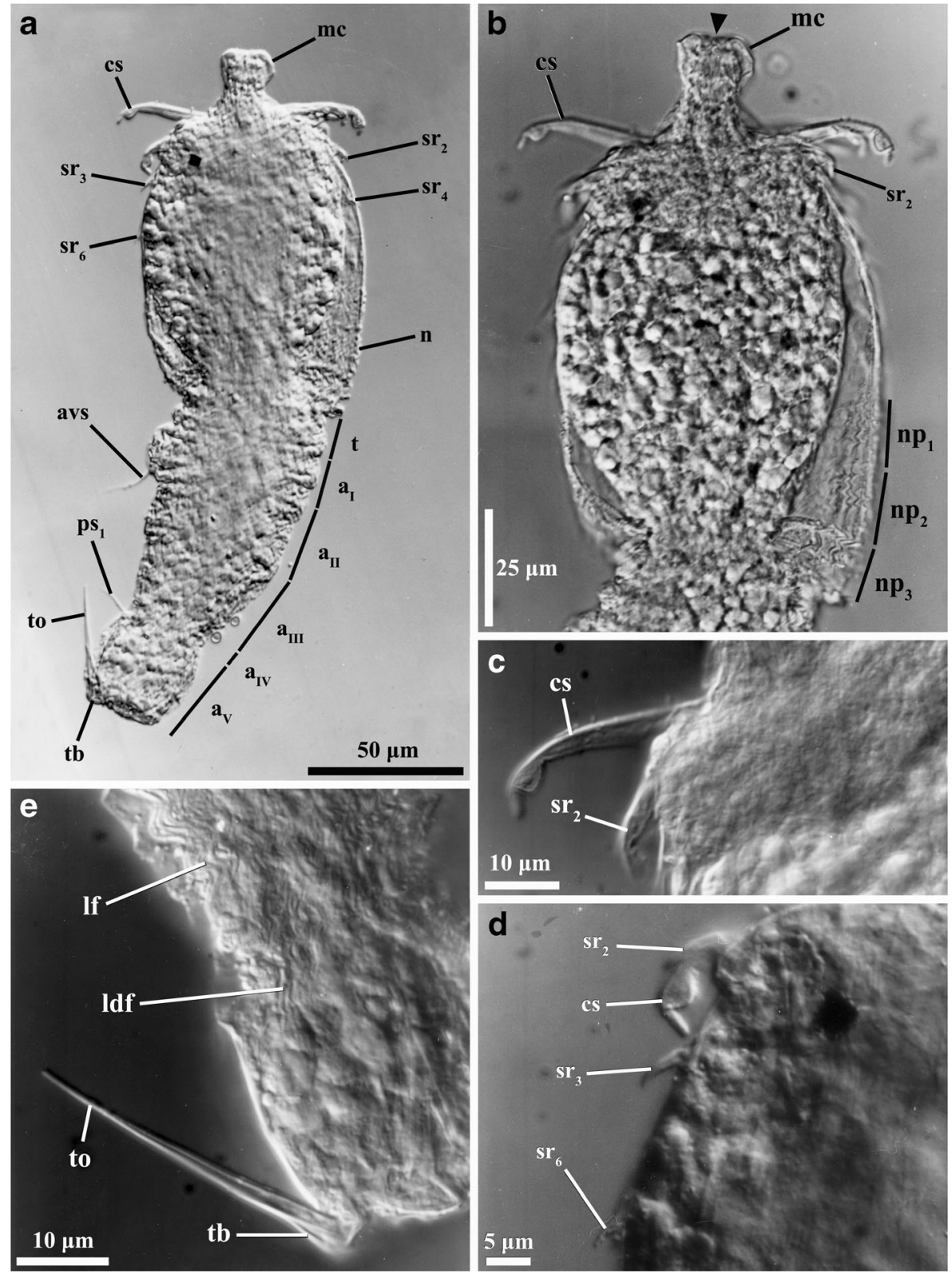

the first sub-region of the abdomen an arrangement of three double rows composed of several small plates. However, these double rows are slightly narrower than those found in the thorax. A single pair of anteroventral setae (avs) is located in the first sub-region of the abdomen. Each seta is unsegmented and characterized by a swollen, large base without folds and a filiform distal region.

The second sub-region ( $\mathrm{a}_{\text {II }}$ ) of the abdomen is similar to the first one, with several fine folds arranged longitudinally in zigzags and crossed by three primary and four secondary transverse folds. This sub-region is arranged in four double rows, each one composed by several small plates (ap). The double rows of the second sub-region are narrower than those of the first sub-region of the abdomen.
The third abdominal sub-region ( $\left.\mathrm{a}_{\text {III }}\right)$ is similar to the two anterior sub-regions although it possesses only half of the number of the longitudinal folds (lf) and lacks the primary transverse folds. The longitudinal folds are undulated rather than in zigzags. The third sub-region is arranged in five rows of plates and the posterior end is narrower than the anterior end.

The fourth abdominal sub-region $\left(\mathrm{a}_{\mathrm{VI}}\right)$ is narrow and collarlike. Several double folds (ldf) are arranged longitudinally, and are aligned with the undulating longitudinal folds present in the third sub-region.

The fifth and most posterior abdominal region $\left(\mathrm{a}_{\mathrm{V}}\right)$ is globular and also possesses longitudinal double folds, which are aligned with those from the fourth sub- region. However, the number of double folds in the fifth sub-region is only half 
Fig. 3 a,b Tenuiloricus shirayamai gen. nov. et sp. nov. Schematic diagrams of the distribution of scalids in the introvert of the Shira larva. a Polar diagram. b Planar projection. cs clavoscalids, $M D$ middorsal line, $M V$ midventral line, $s r_{2-6}$ second to seventh scalid rows, $s s$ spinoscalids

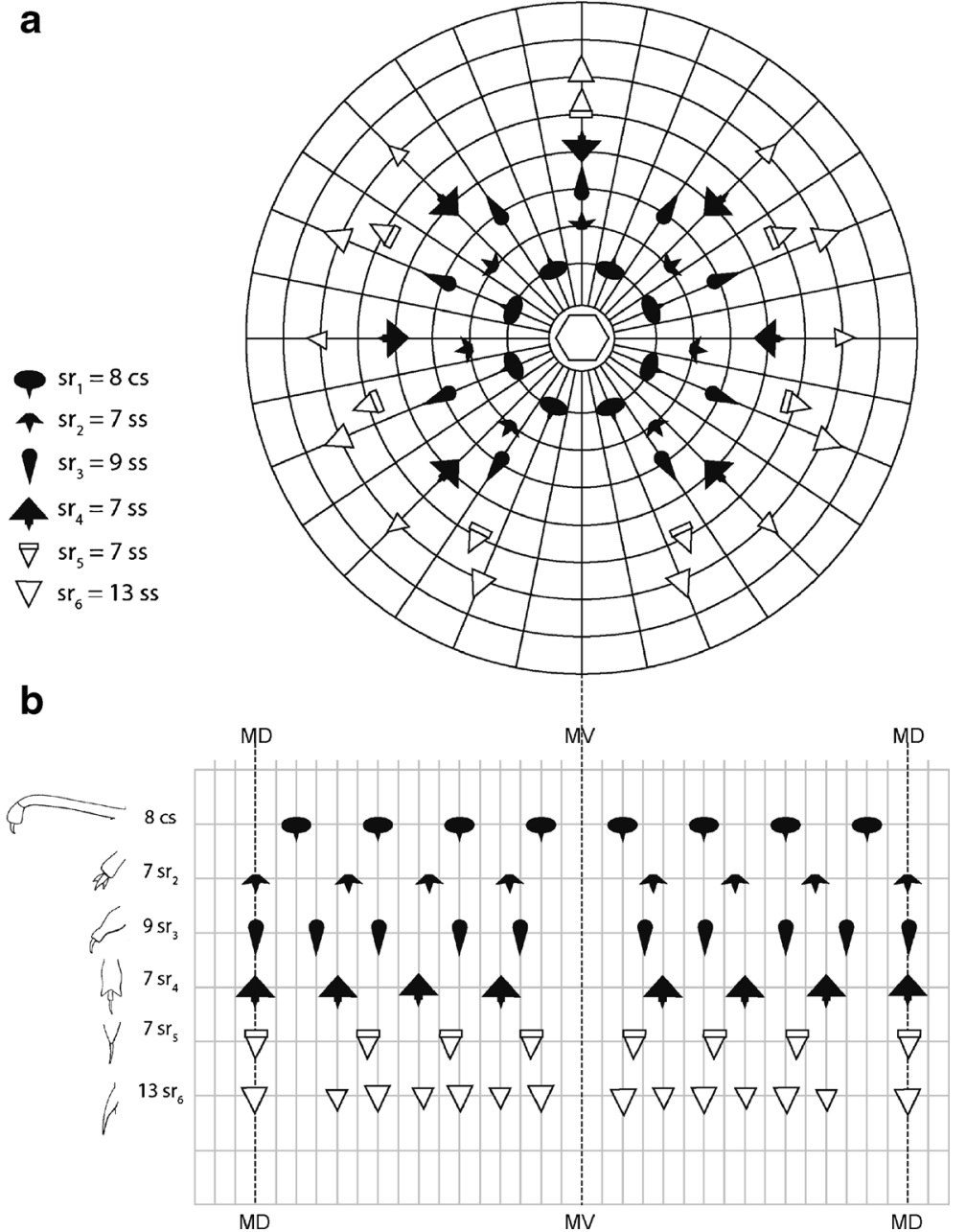

of that in the fourth sub-region. A pair of small, spine-like toes (to) is present ventrally at the posterior end. The toes are characterised by a slightly swollen base, with two longitudinal ridges (tbr), and a pointy tip. Two pairs of setae with pointy tips are located in the posterior region of the abdomen. The posterodorsal setae $\left(\mathrm{ps}_{1}\right)$ are almost as long as the toes, while the posterolateral setae $\left(\mathrm{ps}_{2}\right)$ are small and spine-like.

Internal anatomy (Fig. 1): A narrow buccal channel (bc), lacking internal armature, extends from the mouth opening through the mouth cone and the most anterior region of the introvert. Posteriorly, the buccal channel connects to a very large, oval pharyngeal bulb (pb), which occupies the middle region of the introvert. The region of the mouth cone and the most anterior region of the introvert are characterized internally by the presence of small cells, while most of the volume of the introvert that is below the third row of spinoscalids is occupied by an oval-shaped cluster of large cells. The same type of large cells is present from the neck until the most posterior region of the abdomen though arranged in small clusters. No gonads or gametes have been found in the single investigated specimen.

\section{Differential diagnosis}

The gross morphology of the Shira larva indicates many similarities with the Higgins larvae described in all families of Loricifera (see Table 1). These are, e.g. (1) the eight clavoscalids and six to eight rows of spinoscalids in the introvert, (2) the neck as the closing apparatus, though sometimes a collar region is present, (3) a pair of posterior toes used for locomotion and (4) two or three pairs of posterior sensory setae. However, there are striking differences between the morphology of the Shira larva and the Higgins larva. For instance, the presence of a single pair of anteroventral setae located in the most anterior region of the abdomen is a unique feature found in the Shira larva. In contrast, the Higgins larva possesses always two or three pairs of anterior setae located at the most anterior edge of the loricated abdomen. In addition, the bases of the anteroventral setae are very large and swollen in the Shira larva, which is not the condition observed in the Higgins larva. Another unique feature observed in the Shira larva is the fact that the thorax and abdomen are thinner than the introvert. This condition has never been observed in the Higgins larva of any of the families described so far in the 
Table 1 Comparison of morphological characters between the Higgins larva of families Nanaloricidae, Pliciloricidae and Urnaloricidae and the Shira larva of Tenuiloricus shirayamai gen. nov. et sp. nov. (incertae sedis)

\begin{tabular}{|c|c|c|c|c|}
\hline & \multicolumn{3}{|l|}{ Higgins larva } & \multirow{2}{*}{$\begin{array}{l}\text { Shira larva } \\
\text { incertae sedis }\end{array}$} \\
\hline & Nanaloricidae & Pliciloricidae & Urnaloricidae & \\
\hline \multicolumn{5}{|l|}{ Mouth cone: } \\
\hline Stylets $(n)$ & Absent & Present (6) & Absent & Absent \\
\hline Teeth $(n)$ & Absent & Present (6) & Present (6) & Absent \\
\hline Fringes (double) & Absent & Present (6, only in genus Rugiloricus) & Absent & Absent \\
\hline Valves & Absent & $\begin{array}{l}\text { Present (6, only in genera Rugiloricus } \\
\text { and Titaniloricus) }\end{array}$ & Absent & Absent \\
\hline Midventral oral seta & Absent & Present (only in genus Pliciloricus) & Absent & Absent \\
\hline Internal armature & Absent & Present & Present & Absent \\
\hline \multicolumn{5}{|l|}{ Introvert: } \\
\hline Number of scalid rows & $\begin{array}{l}7 \text { (but only } 6 \text { in genus Armorloricus } \\
\text { because } 2 \text { nd row is absent) }\end{array}$ & $\begin{array}{l}6 \text { (7th row absent in genus Titaniloricus; } \\
\text { 4th or 7th row might be absent in genus } \\
\text { Pliciloricus) or } 7 \text { (in genus Rugiloricus)* }\end{array}$ & $\begin{array}{l}6 \text { (4th row is } \\
\text { missing) }\end{array}$ & $\begin{array}{l}6 \text { ( } 7 \text { th row is } \\
\text { missing) }\end{array}$ \\
\hline Middorsal hook & Absent & Present only in genus Rugiloricus & Absent & Absent \\
\hline \multicolumn{5}{|l|}{ Neck: } \\
\hline Collar region & Absent & Present & Present & Absent \\
\hline \multicolumn{5}{|l|}{ Thorax: } \\
\hline Narrower than introvert & No & No & No & Yes \\
\hline \multicolumn{5}{|l|}{ Abdomen } \\
\hline Narrower than introvert & No & No & No & Yes \\
\hline $\begin{array}{l}\text { Subdivided into five } \\
\text { sub-regions }\end{array}$ & No & No & No & Yes \\
\hline Lorica sculpture & Present (honeycomb-like) & $\begin{array}{l}\text { Present only in Pliciloricus gracilis } \\
\text { (honeycomb-like) }\end{array}$ & Absent & Absent \\
\hline Anteroventral setae & 3 pairs & 2 pairs & 2 pairs & 1 pair \\
\hline Posterior sensory setae & 2-3 pairs & 2-3 pairs & 2 pairs & 2 pairs \\
\hline Flosculi (N-type) & Present & $\begin{array}{l}\text { Present only in some species of the } \\
\text { genus Pliciloricus }\end{array}$ & Absent & Absent \\
\hline Mucrones of the toes & $\begin{array}{l}\text { Present (but absent in genus } \\
\text { Phoeniciloricus) }\end{array}$ & Absent & Absent & Absent \\
\hline
\end{tabular}

*The genus Rugiloricus possesses usually seven rows of scalids; however, the 2 nd and/or the 7 th row is absent in some species

phylum Loricifera. Additionally, the division of the abdominal region into five sub-regions is unique for the Shira larva. In contrast, the Higgins larva always possesses a loricated abdomen as a whole structure.

\section{Discussion}

The larval specimen investigated here is anatomically different from all other larval stages described thus far in phylum Loricifera. Without question, the Shira larva is not a reduced larval stage, such as the ghost-larva of Rugiloricus bacatus or the mega-larva of Urnaloricus gadi (Heiner 2008; Heiner and Kristensen 2008). Indeed, although the Shira larva is rather similar to the Higgins larva in many morphological aspects, a number of features present in the Shira larva are not found in the Higgins larva of any of the three families of
Loricifera, i.e. Nanaloricidae, Pliciloricidae and Urnaloricidae (see Table 1). The presence of a single pair of anteroventral setae with large, swollen bases and the five-partite abdomen thinner than the introvert are unique features found only in the Shira larva.

The clavoscalids of the Shira larva are very similar to those of an undescribed genus belonging to family Pliciloricidae. An extensive description of several species is reported only in an undergraduate thesis (see Gad 2000), though preliminary observations on this new genus are mentioned briefly in a short article (see Gad 2003 and Fig. 1a therein). In this undescribed genus, the clavoscalids of the Higgins larva are tripartite and the most distal segment is spine-like, which is a condition similar to that found in Tenuiloricus shirayamai gen. nov. et sp. nov. Moreover, the thorax and abdomen of the Higgins larva of the new pliciloricid genus are not well separated and each of these regions is composed of 
many plates, which is also a similarity to the Shira larva of Tenuiloricus gen. nov. In the future, a formal description of the new pliciloricid genus will be needed in order to make an accurate comparison with the Shira larva of Tenuiloricus gen. nov.

Indeed, the distinction between the thorax and the abdomen of the Shira larva is difficult to discern. Our interpretation comes from the fact that in the Higgins larvae of all loriciferan genera, including the yet undescribed genus of family Pliciloricidae (cf. Gad 2003), the anteroventral locomotory/ sensory setae are always located at the most anterior boundary of the abdomen. Therefore, the location of the single pair of anteroventral setae is interpreted here as the most anterior abdominal region of the Shira larva. However, this assumption should be confirmed in the future by collecting and investigating other specimens of the Shira larva.

In the Shira larva, the pincer-like spinoscalids of the second row are unique among loriciferans. This character was never found before in any of the already described loriciferan species. In contrast, the spinoscalids of the third to sixth rows are commonly observed in the Higgins larva of all loriciferan families. Indeed, spinoscalids with similar shape can be found, e.g. in Armorloricus kristenseni, Urnaloricus gadi and Pliciloricus diva (Heiner 2004; Heiner and Kristensen 2008; Gad 2009b). A seventh row of spinoscalids was not found in the Shira larva. However, we cannot rule out the possibility that a seventh row of tiny scalids (or even reduced protoscalids) is hidden by the longitudinal and transverse lines that cross the introvert.

The Shira larva of Tenuiloricus shirayamai gen. nov et sp. nov. has some morphological similarities with the Cambrian fossil Orstenoloricus shergoldii (Maas et al. 2009). This fossil is interpreted as a larval stage with phylogenetic affinities to the extant scalidophoran phyla, i.e. Loricifera, Priapulida and Kinorhyncha. The body of $O$. shergoldii is characterised by an accordion-like anterior region with 10-14 folds arranged in zigzag, and a vase-shaped posterior region composed of 20 longitudinal plates. The accordion-like region is identified as a putative neck. In addition, two pairs of spines are present in the abdominal region of $O$. shergoldii: one pair is located at the most anterior edge of the lorica, while the second pair is located posteriorly; both pairs are located at the same side of the body. It is thus interesting to note that both the Shira larva and the Cambrian $O$. shergoldii possess an accordion-like neck region with longitudinal folds arranged in zigzag and a single pair of anterior setae in the abdominal region. Therefore, given the possibility that $O$. shergoldii is a stemgroup loriciferan, the Shira larva could be interpreted as a basal lineage within phylum Loricifera. However, utmost care should be taken before making a final conclusion about this subject.

From the available data, it is not possible to discern much about the life cycle of Tenuiloricus shirayamai gen. nov et sp. nov. The evident similarities to the Higgins larva suggest that T. shirayamai gen. nov et sp. nov. possesses at least a sexual phased life cycle, in which the embryo develops into the Shira larva. In addition, the Shira larva probably molts several times until metamorphoses into a postlarva. However, all these assumptions are speculative. In the future, new sampling of the deep sea area where the single specimen of Shira larva was collected may produce more specimens of $T$. shirayamai gen. nov et sp. nov. and, hopefully, different life cycle stages. A better inspection of distinct life cycle stages of $T$. shirayamai gen. nov et sp. nov. will provide new insights on its internal anatomy, e.g., musculature and nervous system, which is essential to a better understanding of the anatomical bodyplan of phylum Loricifera.

Acknowledgements We are particularly grateful to Prof. Dr. Y. Shirayama (Japan Agency for Marine-Earth Science and Technology, Kyoto University), for the material offered to the Natural History Museum of Denmark. Funding to study the holotype described here was provided partially by EU research exchange programme SYNTHESYS. We thank Prof. Dr. Heinrich Reichert for reading a preliminary version of this article.

\section{References}

Bang-Berthelsen, I. H. (2008). Phylogeny of Loricifera based on combined morphological and molecular studies. Dissertation, University of Copenhagen.

Bang-Berthelsen, I. H., Schmidt-Rhaesa, A., \& Kristensen, R. M. (2012). 6. Loricifera. In A. Schmidt-Rhaesa (Ed.), Handbook of zoology. Gastrotricha, Cycloneuralia and Gnathifera. Vol. 1: Nematomorpha, Priapulida, Kinorhyncha, Loricifera (pp. 307328). Berlin: De Gruyter.

Gad, G. (2000). Studies of systematic, morphology and life cycles of deep-sea Loricifera. Undergraduate dissertation, Carl von Ossietzky Universität, Oldenburg.

Gad, G. (2003). New light on deep-sea Loricifera. Deep-Sea Newsletter, $32,4-5$.

Gad, G. (2004). A new genus of Nanaloricidae (Loricifera) from deep-sea sediments of volcanic origin in the Kilinailau Trench north of Papua New Guinea. Helgoland Marine Research, 58, 40-53.

Gad, G. (2005a). Giant Higgins-larvae with paedogenetic reproduction from the deep sea of the Angola Basin - evidence for a new life cycle and for abyssal gigantism in Loricifera? Organisms, Diversity and Evolution, 5, 44-59.

Gad, G. (2005b). Life history stages of Loricifera: Their morphology and position in the life cycle. Dissertation, Carl von Ossietzky Universität, Oldenburg.

Gad, G. (2005c). Hermaphroditism in Loricifera - as evidenced by Rugiloricus doliolius sp. n. from the Antarctic deep sea. In: Thatje, S., Calcagno, J. A., Arntz, W. E. (Eds.), Evolution of antarctic fauna - extended abstracts of the IBMANT/ANDEEP international symposium and workshop in 2003. Berichte zur Polar- und Meeresforschung, 507, 140-141.

Gad, G. (2009a). Culexiregiloricus, a new genus of Nanaloricidae (Loricifera) from the deep sea of the Guinea Basin (Southeast Atlantic). Zootaxa, 2096, 33-49.

Gad, G. (2009b). A clearly identifiable postlarva in the life cycle of a new species of Pliciloricus (Loricifera) from the deep sea of the Angola Basin. Zootaxa, 2096, 50-81. 
Heiner, I. (2004). Armorloricus kristenseni (Nanaloricidae, Loricifera), a new species from the Faroe Bank (North Atlantic). Helgoland Marine Research, 58, 192-205.

Heiner, I. (2008). Rugiloricus bacatus sp. nov. (Loricifera Pliciloricidae) and a ghost-larva with paedogenetic reproduction. Systematics and Biodiversity, 6, 225-247.

Heiner, I., \& Kristensen, R. M. (2008). Urnaloricus gadi nov. gen. et nov. sp. (Loricifera, Urnaloricidae nov. fam.), an aberrant Loricifera with a viviparous pedogenetic life cycle. Journal of Morphology, 270, 129-153.

Heiner, I., \& Neuhaus, B. (2007). Loricifera from the deep sea at the Galápagos Spreading Center, with a description of Spinoloricus turbatio gen. et sp. nov. (Nanaloricidae). Helgoland Marine Research, 61, 167-182.

Heiner, I., Boesgaard, T. M., \& Kristensen, R. M. (2009). First time discovery of Loricifera from Australian waters and marine caves. Marine Biology Research, 5, 529-546.

Higgins, R. P., \& Kristensen, R. M. (1986). New Loricifera from Southeastern United States coastal waters. Smithsonian Contribution to Zoology, 438, 1-70.

Higgins, R. P., \& Thiel, H. (Eds.). (1988). Introduction to the study of meiofauna. Washington DC: Smithsonian Institution Press.

Kristensen, R. M. (1983). Loricifera, a new phylum with Aschelminthes characters from the meiobenthos. Zeitschrift für Zoologische Systematik und Evolutionsforschung, 21, 163-180.

Kristensen, R. M. (1991a). Loricifera - A general biological and phylogenetic overview. Verhandlungen der Deutschen Zoologischen Gesellschaft, 84, 231-246.
Kristensen, R. M. (1991b). Loricifera. In F. W. Harrison \& E. E. Ruppert (Eds.), Microscopic anatomy of invertebrates (Aschelminthes, Vol. 4, pp. 351-375). New York: Wiley-Liss.

Kristensen, R. M., \& Brooke, S. (2002). Phylum Loricifera. In C. M. Young, M. A. Sewell, \& M. E. Rice (Eds.), Atlas of marine invertebrate larvae (pp. 179-187). London: Academic.

Kristensen, R. M., \& Gad, G. (2004). Armorloricus, a new genus of Loricifera (Nanaloricidae) from Trezen ar Skoden (Roscoff, France). Cahiers de Biologie Marine, 45, 121-156.

Kristensen, R. M., Neves, R. C., \& Gad, G. (2013). First report of Loricifera from the Indian Ocean: a new Rugiloricus-species represented by a hermaphrodite. Cahiers de Biologie Marine, 54, $161-171$.

Maas, A., Waloszek, D., Haug, J. T., \& Müller, K. J. (2009). Loricate larvae (Scalidophora) from the Middle Cambrian of Australia. Memoirs of the Association of Australasian Palaeontologists, 37, 281-302.

Neves, R. C., Bailly, X., Leasi, F., Reichert, H., Sørensen, M. V., \& Kristensen, R. K. (2013). A complete three-dimensional reconstruction of the myoanatomy of Loricifera: comparative morphology of an adult and a Higgins larva stage. Frontiers in Zoology, 10, 19.

Pardos, F., \& Kristensen, R. M. (2013). First record of Loricifera from the Iberian Peninsula, with the description of Rugiloricus manuelae sp. nov., (Loricifera, Pliciloricidae). Helgoland Marine Research. doi: 10.1007/s10152-013-0349-0.

Shirayama, Y. (1984). The abundance of deep sea meiobenthos in the Western Pacific in relation to environmental factors. Oceanologica Acta, 7, 113-121. 